\title{
Formation of the Volunteering Institute in Russia as an Indicator of the Civil Society Development
}

\author{
Isaeva Elena Alexandrovna \\ Candidate of Law, Associate Professor, \\ Chair of Family and Social Legislation at Demidov Yaroslavl State University \\ elenia2000@mail.ru \\ Sokolov Alexander Vladimirovich \\ Candidate of Political Science, Associate Professor, \\ Chair of Social and Political Theories at Demidov Yaroslavl State University \\ alex8119@mail.ru
}

Doi:10.5901/mjss.2015.v6n2s5p402

\section{Abstract}

In conditions of exacerbation of social problems, complexity of modern societies and the limited capacity of public authorities in their decision, attraction and activation of internal resources of the Russian society become urgent for social development. One of these resources is volunteering. Volunteer activities aimed primarily at helping needy segments of the population who can not help themselves due to objective circumstances and conditions (including elderly people, street children, people with disabilities or people who find themselves in the area of natural disasters and social cataclysms). The authors examine the legal conditions for the development of volunteering in Russia at federal and regional levels. They concluded that the potential for citizens' involvement in volunteer activities, at both the regional and federal levels, is higher than the participation itself. The development of the institutional environment for volunteering, including increasing the efficiency of public institutions of social development, are crucial for the actualization and realization of the hidden, untapped potential. Thus, to solve the problems of social development system requires more than just external, but, primarily, internal additional resources, methods of their searching, and technologies of its attraction. Volunteering as a social institution meets the objective challenges of our time and necessity of social and political modernization of regional society and Russian society as a whole.

Keywords: volunteering, civil society, legislation, civil activity

\section{Introduction}

According to the scenario of modernization, Russia in the foreseeable future should become a state, providing social guarantees to citizens to the extent to which a society can not do it itself. It assumes accessibility of basic social services, that are provided free of charge for citizens; the redistribution of social expenditures in favor of the most vulnerable groups, while reducing services for prosperous groups.

At the same time, the possibility of state budget currently allow only soften the situation of the poorest in relation to which state has part of the liability measures; in relation to others - suggests preventive action in order to reduce unemployment and mitigate the effects of mass social risks. It seems that the solution to this problem is the gradual disposal of paternalism in the relationship model between the state and the citizen and the gradual transition to a more efficient mechanism of social adaptation and rehabilitation of socially weaker sections. The main mechanism of the formation and implementation of effective social policies, in our opinion, is to use the resources of civil society and social partnership of government, business and non-profit organizations.

Thus, in conditions of exacerbation of social problems, complexity of modern societies and the limited capacity of public authorities in their decision, attraction and activation of internal resources of the Russian society become urgent for social development. One of these resources is volunteering.

Volunteers, in terms of legislation of the Russian Federation [9], are citizens carrying out charitable activities in the form of unpaid labor in the interests of beneficiaries, including in the interests of a charitable organization without receiving monetary remuneration.

The term "volunteerism (voluntary) work" is often understood as a socially useful activity (individual or collective), 
gratuitously carried out on the basis of good will and free choice in favor of third parties or the public as a whole [6; $p$. 150]. Volunteer activities aimed primarily at helping needy segments of the population who can not help themselves due to objective circumstances and conditions (including elderly people, street children, people with disabilities or people who find themselves in the area of natural disasters and social cataclysms). Volunteering, in terms of active approach, can be defined as a system of public benefit, social and political activities, which includes subjects, objects, motivation, forms, methods and technologies.

Traditionally, volunteerism or volunteer activities are considered either from the sociology point of view - as a way of solving social problems [5], either in terms of pedagogy - as a method of education and socialization [1]. However, in our opinion, volunteering should be considered in a broader perspective - as an institution of civil society and an effective mechanism of civil participation. In the Universal Declaration on Volunteering [12] notes that volunteerism - is "the foundation of civil society, it brings to life the need for peace, freedom, security and justice, it is a way of preserving and strengthening human values, the rights and obligations of citizens, personal growth, through the human capacity realization."

Thus, by understanding social institution (following the neo institutionalisms' theory) as a certain set of rules, formal or informal, and a mechanism to ensure their implementation [2], we can say, that volunteerism, in modern crisis conditions, becomes a social institution that is able to compensate "failures" of market economy, as well as, some of the inefficient functioning of state institutions.

\section{Legal Terms of Volunteering}

The Federal Law (Draft) № 300326-6 «About volunteerism (volunteer work)", submitted on June 21, 2013 to the State Duma of the Russian Federation, by Federation Council members A. A. Borisovym, Yu. L. Vorobevym, V. V. Ryazanskim, deputies of the State Duma V. V. Ivanov, M. A. Kozhevnikovoy, V. M. Kononov became widely discussed in the public sphere as a mechanism of formation the legal basis of volunteerism operation in Russia.

The subject of regulation of the bill is urgent nowadays issue requiring legal regulation. Despite the fact that the use of volunteer labor in Russia already has a long history [14, p. 330] and currently reviving culture of volunteerism is not alien to the large percentage of our citizens (for the last 2-3 years more or less than one-fourth of the Russians were engaged in voluntary and gratuitous public benefit activities [7, p. 13]), the regulatory framework on this issue is not sufficient. The definition of the legal nature of emerging relations within the application of the voluntary labor, the introduction of rules governing these relations, the formation of the conceptual apparatus is necessary. However, , it is important to find a "middle ground" in the process of developing a legal framework for the volunteer labor regulation, without creating bill, which may negatively affect the implementation of voluntary initiatives. Level of involvement in volunteering is a direct measure of self-expression and self-realization of citizens [8, p. 34]. It is also important not to go to opposite extremum - make the framework law contains no specific demanded practice of volunteer labor provisions.

Developers of the bill, in the explanatory note, rightly point out the lack of legal regulation of volunteering (voluntary) activity; indicate the need to improve the legislation in this area. At the same time bill is aimed at a very narrow aspect of the regulation of the volunteer work. Developers excluded from the subject of regulation (part 3, article. 1) activities designed to support NGOs and associations, corporate volunteering, actually bringing the subject of regulation of the bill only to volunteer labor, initiated and organized by the state authorities and local government. Thereby, regulation is aimed at "state volunteers. " In fact, the bill aims at statization of volunteering. Its adoption is aimed at not just volunteer labor regulation, but is dedicated at "facilitating the implementation of the functions of the organs of state power and local self-government" (Part 2 of Article 3 of the Bill). Based on the text of the bill this direction is displayed as a primary. For "non-system" volunteers this bill does not bring nothing new in the sphere of legal regulation.

In addition, Part 2 of Art. 10 of the law draft contains an indication that in order "to attract volunteers for elimination of emergency situations on municipal, inter-municipal, regional, inter-regional and federal level, only organizer of the volunteer activity is entitled to do this. Normally, it is state authority or local governments and organizations dealing with emergencies in accordance with the legislation of the Russian Federation. Accordingly, citizens who wish to take part in extinguishing fires or flood relief does not have the right to help the victims without admission of the authority that seriously reduces the value of the bill in terms of development of volunteerism, and strengthening mutual traditions in Russia [11].

The bill, in contrast to its previous version, proposed by developers in January 2013 and caused a storm of public indignation, is not focused on creation of a unified closed registry of volunteers. The previous version of the bill in Article 14 includes provisions that all information contained on a national registry of volunteers are personal data and can not be transferred to third parties, except as stipulated by the legislation the Russian Federation. Based on the wording, only 
authorized body have access to the registry of volunteers. Thus, only state will be able to use the base, which a priori seriously impair the value of the registry. Every region of Russia is given the right to make decision on the establishment and maintenance of information resources, involving the registration of volunteers, and issuance of identification number.

Particularly every subject of the Russian Federation independently defines the need of conducting an information resource. The bill does not specify whether or not information resource will be public or private, will be used only by the authorities or by any persons in the region, this enables region to determine on their own the order of disclosure information about volunteers.

If any region of Russia for some financial or organizational reasons come to the conclusion that there is no possibility of forming its own portal, than it deprived volunteers of the right to "enter information on its implementation of the volunteer activity, location and number of hours and promotion, he had received additional training; the right to receive support and incentives" (claims 7 Part 3 of Art. 6 of the Draft Law). Realization of other rights, as stated in Part 3 of Art. Bill 6, without registration on the information portal can be questioned. In particular, obtaining letters of recommendation, work wear reimbursement for travel, possibility to obtain government awards. It can be assumed, that the registers will still be conducted in regions, but without the requirements of the federal law on data transparency of volunteers and the possibility of CO NGOs in the region to use information resource. Registers will turn out, as in the previous version of the bill "On volunteering," as just lists for official use, the list of "state volunteers" [4].

The closure of the voluntary initiatives within the closed system gives reason to believe that the bill is still aimed at the creation of the state volunteering system, including tools of budget savings (in support of the position we refer to the explanatory note, which states that "the state is interested in development of volunteering activities .... and in terms of improving the economic effect of the volunteer work"

The bill includes a provision on the duty to maintain the confidentiality of information to which the volunteer has access in the course of volunteer activities (claims 4. H. 4 Art. 6). Well as the obligation not to interfere with realization of state and local officers duties. In fact, volunteer is becoming a person, that should work free of charge, strictly obey the instructions of the authorities, do not have the right to act without a special permit, and disclose what they saw / heard, and without opportunity to influence the decision-making process. In addition, a volunteer becomes a tool of implementation of the authorities' functions, which will, after signing the contract, is not taken into account, due to some limitations of their rights to terminate the contract unilaterally (claim 2 p. 3 art. 6 of the Draft Law). This violates Art. 37 of the Russian Constitution.

The experience of countries on conducting a clear definition of the status of volunteer demonstrates that despite the destination from labor legislation, volunteer is under the state protection to give certain guarantees and benefits. Important issue is about insurance for volunteers. For example, in Turkey insurance of volunteers is obligatory, in Albania volunteers supposed to be registered in the Employment Bureau. On the one hand, it seriously complicates the process of attracting volunteers for organizations, but if the event is financed by the State, the risks can be reduced. For example, in New Zealand and South Korea, the government provides insurance for volunteers if their work is associated with health risks. In Poland, volunteers have many benefits, such as accommodation expenses and subsistence expenses in the same amount as in the case of wage earners, compensation for other necessary expenses eligible for maintenance during illness and others. Moreover, this law introduces additional benefits for volunteers, delegated to work in other countries, such as medical insurance for foreign workers, insurance against injury, additional costs of travel and other.

An important aspect of the volunteer legal status is having the status of unemployed and receiving unemployment benefits. If an unemployed volunteer working as a volunteer, unemployment benefits should not be lost. For example, this issue has been resolved in the Czech Republic. In Macedonia, the Law on Volunteerism (2007) liberated themselves from taxation of the costs associated with volunteering, and made clear, that unemployed person does not lose the right to receive benefits if they are volunteers. This removed barriers for unemployed participation in volunteering, creating incentives for public volunteering for all individuals within a single legislative act. In Moldova the experience of volunteering counts as work experience and taken into account when calculating pensions.

Important legal issue in the regulation of volunteer work is related to its taxation. International practice shows good examples of this aspect of the regulation. For example, Polish law provides for tax exemption amount of compensation made by the volunteer organization of any organizational and legal form. In Lithuania compensation for volunteer work, is not considered as income, so is not taxed.

Based on foreign experience, basic content regulation on volunteering can perform the following:

- $\quad$ The definition of "volunteer" and "volunteering";

- The definition of "host organization";

- The content of the volunteer agreement and its conditions;

- The rights and obligations of the volunteer and the host organization in relation to each other; 
- The provisions on liability, which apply to persons who violate the rules of volunteer activities;

- Taxes on the costs associated with the implementation of volunteer activities, such as travel costs, accommodation;

- Incentives for people to take part in volunteer activities, such as social benefits, contributions to the unemployment benefit;

- Terms of international volunteering, namely, voluntary activities of their citizens abroad and foreign citizens in the country.

Foreign experience demonstrates different models for the formation of legislation on volunteering: it may be provisions scattered in various regulations, and may be a separate comprehensive law on volunteering. This is the most commonly used model of regulation in Europe when all the provisions governing the volunteer activities, are combined into one single document. For example, the law of Macedonia provides a detailed description of the rights and responsibilities of volunteers and host organizations, terms of taxation applicable to reimbursement, volunteers' insurance conditions and determines responsibility for the offense.

A well-designed separate law can be an effective tool to promote volunteer activity, and in conjunction with national policies and strategies can contribute to the development of volunteer traditions in the country.

\section{Development of Volunteering (Sociological Dimension)}

Sociological studies of volunteering show a high degree of willingness of the population for volunteer activities. Thus, according to the WCIOM interrogation, $75 \%$ of young Russians are ready to engage in socially useful activities free of charge or for a nominal fee. $48 \%$ of young already have experience of such participation [13]. 53\% of Russians worked voluntarily at least once for the benefit of society in the last five years.

Researchers from Center for Civil Society Studies and the nonprofit sector (HSE) at the Conference "Development Strategy of volunteering in Russia - 2020 Roadmap" noted that Russian organized volunteering covers only $3 \%$ of adult respondents (909 of those surveyed). However, it has a high potential: 37\% of respondents (10680 people) were included in finding solution for social problems in the community. Thus, the lag between the data from these two studies can be defined as the potential for the development of volunteering in Russia.

Leading motive of participation in volunteer activities is the desire to be helpful for those in need (58\%). Much less, people are doing it in order to solve a problem (14\%), because of the desire to share with others how to resolve it, to pay back good for good (12\%). Some also noted that volunteers are becoming people for their own pleasure (17\%), recreational and entertainment (12\%), obtaining useful skills (5\%), meeting new people (4\%).

In 2013, three studies were carried out in order to find out regional characteristics of volunteering in the Yaroslavl region:

- Telephone survey by sample in 639 adult residents of the Yaroslavl region (statistically representative sample by gender and age, the standard error of the sample 3. 9);

- Survey of executives of 54 non-profit organizations of the Yaroslavl region.

- A survey of 52 federal and local authorities' representative

For each of this group unique questionnaire had been developed that allows taking into account the role of each entity in the implementation of a particular type of civic engagement.

- Research has shown that volunteering in the Yaroslavl region developed at an average level - 4. 2 points (on a scale of 1 - 10 points). Authority, population and representatives of NGOs are almost equally in this issue (Table 1).

Table 1. What do you think about the degree to which volunteering is developed in the Yaroslavl region? (from 1 to 10)

\begin{tabular}{|c|c|}
\hline & Average \\
\hline Population & 4,22 \\
\hline NGO representatives & 4,22 \\
\hline Officials & 4,24 \\
\hline
\end{tabular}

A serious obstacle for the development of volunteering is the low level of activity of the population. According to a study conducted in the Yaroslavl region, more than half of the inhabitants exclude (38\%) or rather exclude the possibility (17\%) of gratuitous personal participation in any public associations, organizations, initiative groups. This figure is slightly higher than the nationwide identified in the study of "Public Opinion" Foundation in 2013 (49\%) [10]. The main reasons for non- 
participation are lack of understanding of personal benefits from participation in public life, lack of time, lack of initiative groups to be joined.

$20 \%$ of the surveyed allow, and $22 \%$ - rather admit for themselves gratuitously work in any public associations, organizations and initiative groups. Most of those who are willing to engage in active civil procedure (42\% of the Yaroslavl region) are 18-29 years old, as well as those of middle age - 30-49 years, mostly with higher education; every two respondents from these socio-demographic categories indicated that prevent or rather permit gratuitous private participation in any public associations, organizations, initiative groups. Civic duty or opportunity to contribute to the solution of socially significant problems are the main mentioned factors of participation. Apparently, this is the main component we need to emphasis in the promotion of volunteering. Especially when such work is necessary in order to bring the importance and benefits of volunteering for all.

For $81 \%$ of the surveyed executives the work of NGOs is inconceivable without the labor of volunteers. Most often, such need arises while orginising NGO activities (78\%). A number of non-governmental organizations ensure the information support of NGO activities (33\%) on a voluntary basis. Number of volunteers in the organization strongly depends on the scale of activities. Thus, the number of volunteers in the surveyed organizations ranged from 0 to 350 , and the number of hours per month when volunteer is involved in the organization - from 0 to 200.

Leaders of non-profit organizations indicate that most prone categories for volunteering are students $(74 \%)$, pensioners (50\%), and pupils (37\%). Main challenges of working with volunteers are motivation, lack of time and lack of stuff member responsible for them (28\%), lack of practice to attract volunteers (26\%), and unsystematic nature of working with volunteers (26\%). According to surveyed executives of NGOs, greater coverage of the non-profit and public organizations in the media (48\%), more active government support of the volunteer movement (44\%), the positive image of non-profit organizations and volunteering in the public consciousness (40\%) are the main catalysts for the development of volunteering.

Table 2. What could encourage greater involvement of volunteers in non-profit and community organizations? (NGO representatives)

\begin{tabular}{|l|c|}
\hline Answer & $\%$ \\
\hline Increased coverage of non-profit and public organizations activities in the media & $48,1 \%$ \\
\hline More active government support of the volunteer movement & $44,4 \%$ \\
\hline Creating a positive image of non-governmental organizations, as well as volunteering in the public consciousness & $38,9 \%$ \\
\hline More active encouragement of volunteers & $35,2 \%$ \\
\hline More active work of non-profit and community organizations with a society & $22,2 \%$ \\
\hline
\end{tabular}

In this regard, a large-scale information campaign on a wider coverage of the work of NGOs, as well as a positive image of public organizations and volunteering, aimed at addressing the lack of awareness among the population, could contribute to the rapid development of NGOs and volunteering. Non-governmental organizations must be ready to talk openly about their work. Therefore, the objectives of the organization are not just to create informational occasion, but make it interesting for the audience and the media. Creative and modern approach to outreach is needed today, in order to attract someone as volunteers in the future.

Most of the surveyed executives of NGOs say that they do not form relationship with volunteers (80\%). As a key motivational stimulus NGO's representatives use gratitude and certificates (52\%), obtaining new skills (46\%), recommendations / positive characteristics of employment (41\%).

$85 \%$ of authorities are aware about the necessity to develop the volunteer movement. Among the mechanisms that need to be developed, the experts proposed the following:

- Adoption of a law on volunteering;

- Informational support of projects;

- Promotion of volunteer work in educational institutions;

- Network development for volunteer centers, united by a common mission and activities;

- Improving professional competence of specialists working in the field of volunteer resources, non-profit organizations, business organizations, educational institutions, community groups, through the development and implementation of training programs in order to increase efficiency of the volunteer organizations;

- Multiplication of funding for youth involvement in volunteer activities (visual materials, promotion, education);

- The creation of a favorable image of volunteers, introduction of non-financial incentives of volunteers (training seminars, etc. ). 


\section{Conclusions}

Based on the above it can be concluded that conceptual approach is needed to ensure wide development of the institution of volunteering in Russia, and filling gaps in legislation with respect of volunteers in the broadest sense of the term.

The value of developing a culture of volunteerism for the state is difficult to overestimate. In addition, it is an integral part of civil society, contributing to its development and prosperity. The value of volunteering can be measured in terms of social and economic capital. In particular, competent normative regulation of this institution can contribute to the support of the priorities, selected by the government, the achievement of certain social goals through the resource of volunteers. Within this block, norms of citizen engagement in volunteer activities at the level of legal regulation may be generated within the priority areas for the state. For example, some areas in which, according to the State, volunteers are especially in need (social services, health care, and others. ), can be identified as well as mechanisms for their engaging and stimulating.

The value of volunteer resources, in the implementation of large state mechanism for responding to emergencies, is huge. Mechanism of regulation of voluntary activity should allow the state, in a critical situation, using incentives, direct volunteer streams in the desired direction (firefighting, elimination of consequences of floods, etc. ).

In the development of legislation on volunteering, it is necessary to consider encouraging norms. For example, financial and material assistance to the volunteers involved in firefighting and rescue operations, as well as loans and benefits from employers, workers and universities who participated in the liquidation of emergency situations. Compensation for volunteering can serve as exemption from military service.

In a situation of rising unemployment, low mobility and reorientation of persons who lost their jobs or do not have work experience, well formed Institute of Volunteering can play a positive role. For example, the program to involve the unemployed in volunteer programs will lead to the acquisition of new skills as part of a community service; the introduction of evaluation certificates, which can serve as an official confirmation of passing the professional internship, will contribute to the unemployed to find work.

As an incentive, credit system for volunteers can be used. For example, in 2005 the Department of Taxation in New Zealand amended the "Principles of lending students" so that students wishing to take out a loan were able to work in the specified charitable organizations as volunteers or for a nominal fee, and thus be eligible for a two-year exemption from payment of interest.

It is necessary to determine the precise legal status of volunteers, and make a distinction between employee and volunteer in the national legislation in order to develop the institute of volunteerism. Disregard of the legislator to the delimitation of legal status, puts organization, which uses volunteer labor, under the threat of accountability for noncompliance with labor laws. Russian labor legislation does not contain the feasibility of using labor free of charge, which complicates the understanding of the structure by controlling bodies.

Initiatives, related to the development of volunteerism in Russia, should take into account national characteristics and include mechanisms that can positively affect the elimination of the bad image of volunteering in Russia "compulsory" volunteering in support of government priorities (work not on heart call, but in the direction of the state by using enforcement mechanisms). Mechanism for creation a culture of volunteerism are important. We have to enter volunteering into the system of education, in order to involve students in volunteer projects. For example, schools can enter a "day of volunteering", which would take place for all age groups. Each class can spend the day, doing appropriate for their particular age.

In summary, we can conclude that the potential for citizens' involvement in volunteer activities, at both the regional and federal levels, is higher than the participation itself. The development of the institutional environment for volunteering, including increasing the efficiency of public institutions of social development, are crucial for the actualization and realization of the hidden, untapped potential. Thus, to solve the problems of social development system requires more than just external, but, primarily, internal additional resources, methods of their searching, and technologies of its attraction. Volunteering as a social institution meets the objective challenges of our time and necessity of social and political modernization of regional society and Russian society as a whole.

\section{Acknowledgement}

The study was sponsored by the Ministry of Education and Science of the Russian Federation under the basic portion of the state scientific research of Demidov Yaroslavl State university, project number 1127 "Legal and socio-political aspects of civic engagement in modern Russia" 


\section{References}

Arapov M. O. 2013. Interaction of cultural institutions activities and volunteer movement on the formation of social qualities of youth: Abstract. Thesis... Phd. - Moscow.

Auzan A. A. 2010. Institutional Economics. New Institutional Economic theory. Moscow: INFRA-M.

Holina O. I. 2011. Volunteering as a social phenomenon of modern Russian society. - Theory and practice of social development. № 8. Isaeva E. A. Nationalization of the of volunteering institute in Russia: Analysis of the bill "On volunteering" Power. 2013. № 10.

Kudrinskaya L. A. 2006. Volunteer work: the experience of theoretical reconstruction: abstract. Thesis ... Phd. Sociological science, Moscow.

Loginova N. V. 2012 Volunteering as social phenomenon: the experience of presentation of the conceptual vocabulary. Political Linguistics № (41).

Mersiyanova I. V. The involvement of the population in the informal practices of civil society and NGO activities. Moscow, 2011. P. 98; Mersiyanova I. V. Differentiation of the Russian regions in the context of prerequisites for the formation of civil society // Power. 2008. №8.

Mordasova T. A. The social model of charity as a factor of civil society institutions development // Caspian region: politics, economy, culture. - 2009. №4.

On Charity and Charitable Organizations: Federal Law of 11 August 1995 N 135-FZ (rev. May 5, 2014) // Legal System GARANT: http: //base. garant. ru/104232/\#ixzz3GZ43GD6I (tested 10. 11. 2014).

Resource of the volunteer movement of avant-garde groups for Russia's modernization. Report FOM, July 2012 Access: http: //soc. fom. ru/uploads/files/dobrovolchestvo/Otchet_dobrovolchestvo. pdf (tested 10. 11. 2014).

Sokolov A. V. , Solovyova A. V. Network civil movements (for example, "Musora. Bolshe. Net. ") // Power. 2012. №12.

The Universal Declaration on Volunteering. Access: http: //www. kdobru. ru/materials/Bcеобщая Declaration Dobrovolchestva. pdf (tested 10. 14. 2014).

Volunteering in Russia: the potential of youth participation. Access: http: //wciom. ru/index. php?id=459\&uid=111713/ (tested 11. 10. 2014).

Voronova E. A. Volunteering as a form philanthropy in contemporary Russia // Vestnik St. Petersburg University. Series 12. Psychology. Sociology. Pedagogy. 2011. №1. 